\title{
Aplicación de un Ciclo de Mejora en el Aula en la asignatura "Curso Monográfico de Ensayo Hispanoamericano"
}

\section{Improvement Cycle in Classroom applied to the subject "Curso Monográfico de Ensayo Hispanoamericano"}

SABINA REYES DE LAS CASAS

https://orcid.org/0000-0002-0937-2164

Universidad de Sevilla

Departamento de Literatura

Española e Hispanoamericana

sreyes2@us.es

DOI: http://dx.doi.org/10.12795/9788447231003.057

Pp.: $1207-1228$ 


\section{Breve descripción del contexto}

El "Curso Monográfico de Ensayo Hispanoamericano" es una asignatura optativa de tercer curso del Grado en Filología Hispánica (Universidad de Sevilla). En el año académico 2020-2021 contamos con 67 estudiantes matriculados, algunos de ellos Erasmus cuyo conocimiento del idioma y de la literatura hispanoamericana varía bastante. De los estudiantes matriculados, suelen asistir (virtual o presencialmente) entre cuarenta y sesenta, dependiendo del día. sin embargo, no todos los estudiantes matriculados se muestran interesados en realizar las actividades propuestas durante la implantación de nuestro Ciclo de Mejora en el Aula (CIMA), pues algunos son repetidores que tienen la intención de presentarse a la convocatoria extraordinaria de diciembre.

Por otro lado, es importante tener en cuenta que al comenzar en octubre el curso 2020-2021 la Facultad de Filología optó por un sistema híbrido o mixto de docencia. Mediante este sistema, un grupo formado por un tercio de la clase podía estar de forma presencial en el aula, mientras que los dos tercios restantes seguían la sesión de forma síncrona. Estos grupos se iban rotando semanalmente. Además, durante la implantación del CIMA la Junta de Andalucía decretó que la docencia universitaria pasase a una modalidad $100 \%$ en línea, lo que nos obligó a adaptarnos a esta nueva circunstancia.

\section{Diseño previo del CIMA}

\section{Mapa de contenidos y problemas}

Los contenidos conceptuales, procedimentales y actitudinales de nuestro CIMA se encuentran estructurados a partir de una pregunta general motivadora (“¿Cómo se construye la identidad nacional puertorriqueña?") a la que

Ciclos de Mejora en el Aula (2020). Experiencias de Innovación Docente de la US Esta obra se distribuye con la licencia Creative Commons 
los estudiantes tendrán que dar respuesta mediante la realización de las distintas actividades de contraste llevadas a cabo durante las sesiones y también a través de la presentación de una actividad o proyecto final que consiste en la realización de un artículo divulgativo que elaborarán en grupos de cinco estudiantes. Cada uno de esos artículos formará parte de una revista homenaje al ensayista que tenemos que estudiar en este módulo del curso: Antonio S. Pedreira, autor de Insularismo (1934). Por tanto, "el estudiante se concibe en todo momento como un sujeto activo frente a su aprendizaje [...] Él tiene la posibilidad de dirigir su propio aprendizaje, a través de los equipos de trabajo." (Ortiz, Calderón y Travieso, 2016: 13).

A continuación, incluimos un esquema que sintetiza los contenidos y problemas que hemos tratado en las distintas sesiones durante las cuales hemos aplicado nuestro CIMA (Figura 1). Dichos contenidos están estructurados a partir de esa pregunta motivadora o significativa que hemos propuesto a los estudiantes.

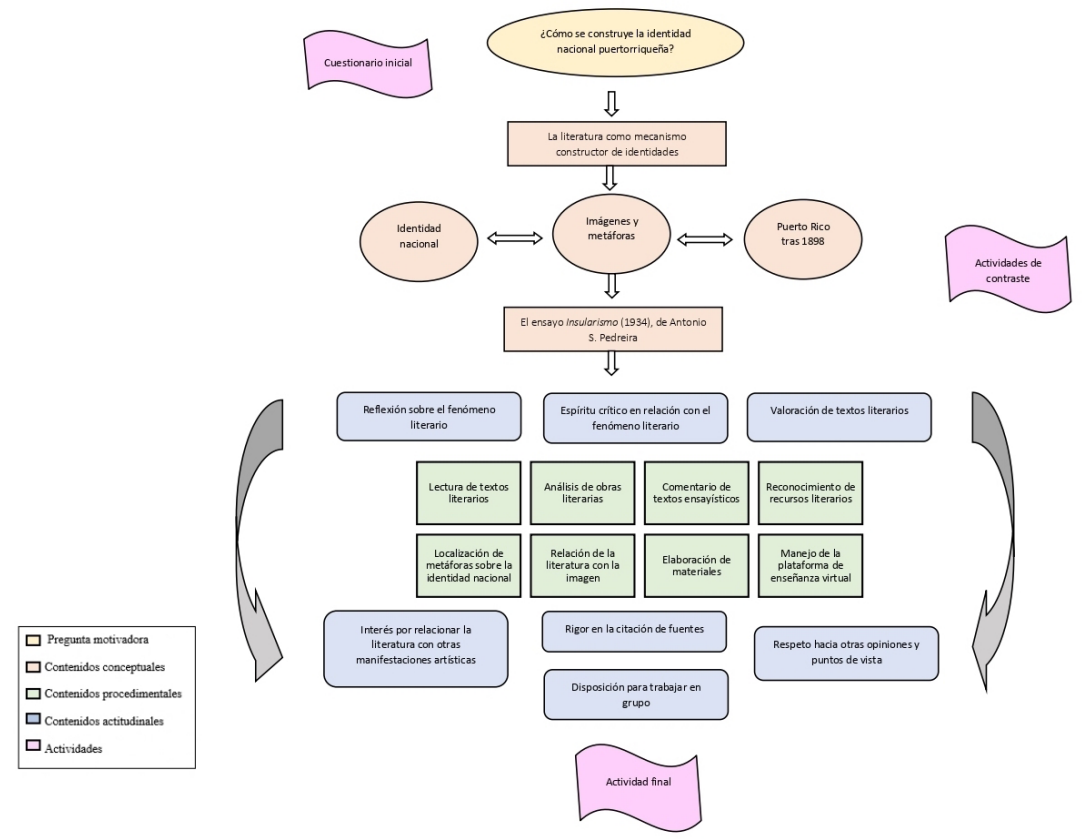

Figura 1. Mapa de contenidos y problemas

Ciclos de Mejora en el Aula (2020). Experiencias de Innovación Docente de la US Esta obra se distribuye con la licencia Creative Commons 


\section{Modelo metodológico posible y secuenciación de actividades}

Aunque nuestro modelo metodológico presenta algunas pequeñas variantes, podemos representarlo a través del esquema recogido en la Figura 2.

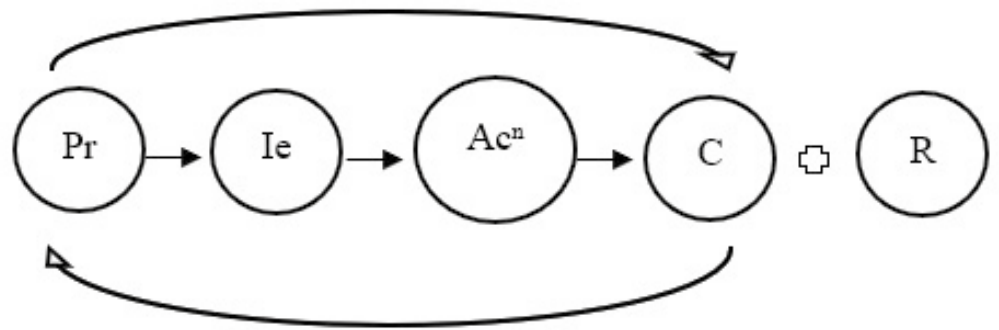

Figura 2. Modelo metodológico posible

Partimos de un "problema" (Pr) o reto que plantearemos al alumnado. Para conocer sus conocimientos previos sobre el tema, realizaremos un cuestionario inicial que se corresponde con lo que denominamos "Ideas de los estudiantes" (Ie). Los estudiantes trabajarán en pequeños grupos de cinco personas para tratar de dar respuesta a ese problema a través de distintas "Actividades de Contraste" $(A C)$. Una vez que cada grupo haya planteado una posible solución al problema, pasaremos a una nueva fase de "Actividades de contraste" ( $\left.A C^{2}\right)$, donde serán los propios alumnos quienes pongan en común lo que han trabajado en los distintos grupos para debatir acerca de la postura de cada uno de ellos, localizando similitudes y diferencias y completando así un esquema que sirva para dar respuesta al problema inicial planteado. Asimismo, la profesora propondrá, junto con los alumnos, una "Conclusión" (C) o sintesis de las principales ideas y conceptos que han surgido durante las distintas sesiones de trabajo a partir de las propias ideas aportadas por los estudiantes.

Ciclos de Mejora en el Aula (2020). Experiencias de Innovación Docente de la US Esta obra se distribuye con la licencia Creative Commons 
Por último, es importante señalar que, una vez terminado el CIMA, los alumnos tendrán que entregar el resultado del proyecto inicialmente propuesto (R). Esta actividad la habrán realizado de forma autónoma, pero teniendo siempre en cuenta que "el profesor debe brindar una orientación lo más completa posible de los contenidos y de las tareas que debe realizar el estudiante, así como establecer un acompañamiento durante el proceso atendiendo a las diferencias individuales de los estudiantes y de los equipos de trabajo. Además, debe diseñar y brindar cuando sea necesario un sistema de ayudas al estudiante para que logre un desarrollo substancial de sus potencialidades." (Ortiz et al., 2016: 13).

A continuación, presentamos de forma sintetizada la secuencia de actividades propuestas en cada una de las sesiones de nuestro CIMA:

Tabla 1. Secuenciación de actividades

\begin{tabular}{|c|c|c|c|}
\hline \multicolumn{4}{|c|}{ PRIMERA SESIÓN } \\
\hline Actividad & Temporización & Descripción & Recursos \\
\hline $\begin{array}{l}\text { 1. Presentación } \\
\text { del problema }\end{array}$ & 20 minutos & $\begin{array}{l}\text { Presentación del proyecto, } \\
\text { calendario de actividades, } \\
\text { evaluación y recursos } \\
\text { disponibles en la plataforma } \\
\text { de Enseñanza Virtual }\end{array}$ & $\begin{array}{l}\text { Diapositivas, } \\
\text { documento } \\
\text { "Actividad Final" } \\
\text { y documento } \\
\text { "Textos". } \\
\text { plataforma de } \\
\text { Enseñanza Virtual }\end{array}$ \\
\hline $\begin{array}{l}\text { 2. Realización } \\
\text { del } \\
\text { cuestionario } \\
\text { inicial (le) }\end{array}$ & minutos & $\begin{array}{l}\text { Realización del cuestionario } \\
\text { de exploración a través } \\
\text { de la plataforma (Recurso } \\
\text { habilitado - Encuestas). Los } \\
\text { alumnos que están en clase } \\
\text { de forma presencial podrán } \\
\text { realizarlo en papel }\end{array}$ & $\begin{array}{l}\text { Fotocopias del } \\
\text { cuestionario. } \\
\text { Encuesta en } \\
\text { la plataforma } \\
\text { de Enseñanza } \\
\text { Virtual. }\end{array}$ \\
\hline
\end{tabular}

Ciclos de Mejora en el Aula (2020). Experiencias de Innovación Docente de la US Esta obra se distribuye con la licencia Creative Commons 


\begin{tabular}{|c|c|c|c|}
\hline $\begin{array}{l}\text { 3. Debate sobre } \\
\text { los conceptos } \\
\text { e ideas del } \\
\text { cuestionario } \\
\text { inicial (AC) }\end{array}$ & 30 minutos & $\begin{array}{c}\text { Conocer las ideas previas del } \\
\text { alumnado (IA) y debatir sobre } \\
\text { ellas (AC) }\end{array}$ & $\begin{array}{c}\text { Diapositivas. } \\
\text { Plataforma de } \\
\text { Enseñanza Virtual }\end{array}$ \\
\hline $\begin{array}{l}\text { 4. ¿Qué tienes } \\
\text { que hacer para } \\
\text { mañana? }\end{array}$ & 10 minutos & $\begin{array}{l}\text { Sintesis de la clase (S). } \\
\text { Recordatorio de las } \\
\text { actividades que el alumno } \\
\text { tiene que hacer para al día } \\
\text { siguiente y de las vías de } \\
\text { comunicación }\end{array}$ & $\begin{array}{c}\text { Diapositivas. } \\
\text { Plataforma de } \\
\text { Enseñanza Virtual }\end{array}$ \\
\hline \multicolumn{4}{|c|}{ SEGUNDA SESIÓN } \\
\hline $\begin{array}{l}\text { 1. Proyección } \\
\text { de imágenes } \\
\text { y diálogo en } \\
\text { torno a ellas } \\
\text { (AC) }\end{array}$ & 30 minutos & $\begin{array}{l}\text { El objetivo de esta actividad } \\
\text { es que el alumnado se } \\
\text { vaya familiarizando con la } \\
\text { utilización de las metáforas } \\
\text { como mecanismo de } \\
\text { construcción de la identidad } \\
\text { nacional en el ensayo que } \\
\text { tienen que analizar y valorar. } \\
\text { En este caso, partiremos de lo } \\
\text { más fácilmente identificable: } \\
\text { metáforas visuales }\end{array}$ & $\begin{array}{c}\text { Diapositivas. } \\
\text { Plataforma de } \\
\text { Enseñanza Virtual }\end{array}$ \\
\hline $\begin{array}{l}\text { 2. Lectura y } \\
\text { comentario } \\
\text { de fragmentos } \\
\text { (AC) }\end{array}$ & 30 minutos & $\begin{array}{l}\text { El objetivo de esta actividad } \\
\text { es que el alumnado se } \\
\text { vaya familiarizando con la } \\
\text { utilización de metáforas como } \\
\text { mecanismo de construcción } \\
\text { de la identidad nacional } \\
\text { dentro del ensayo que tienen } \\
\text { que analizar y valorar. Para } \\
\text { ello, utilizaremos algunos } \\
\text { fragmentos seleccionados } \\
\text { del cuadernillo de textos } \\
\text { que tienen disponible en la } \\
\text { plataforma }\end{array}$ & $\begin{array}{l}\text { Diapositivas, } \\
\text { cuadernillo } \\
\text { “Textos” (cuya } \\
\text { lectura previa } \\
\text { les habremos } \\
\text { recomendado } \\
\text { en la sesión } \\
\text { anterior). } \\
\text { Plataforma de } \\
\text { Enseñanza Virtual }\end{array}$ \\
\hline
\end{tabular}

Ciclos de Mejora en el Aula (2020). Experiencias de Innovación Docente de la US Esta obra se distribuye con la licencia Creative Commons 


\begin{tabular}{|c|c|c|c|}
\hline 3. Sintesis (C) & 10 minutos & $\begin{array}{l}\text { A partir de los comentarios } \\
\text { y aportaciones de los } \\
\text { estudiantes, la profesora } \\
\text { propone una sintesis de las } \\
\text { principales ideas tratadas } \\
\text { durante la sesión }\end{array}$ & $\begin{array}{l}\text { Plataforma de } \\
\text { Enseñanza Virtual }\end{array}$ \\
\hline $\begin{array}{l}\text { 4. ¿Qué tienes } \\
\text { que hacer para } \\
\text { mañana? }\end{array}$ & 10 minutos & $\begin{array}{c}\text { Recordatorio de las } \\
\text { actividades que el alumno } \\
\text { tiene que hacer para al día } \\
\text { siguiente y de las vías de } \\
\text { comunicación. Resolución de } \\
\text { dudas }\end{array}$ & $\begin{array}{c}\text { Diapositivas. } \\
\text { Plataforma de } \\
\text { Enseñanza Virtual }\end{array}$ \\
\hline \multicolumn{4}{|c|}{ TERCERA SESIÓN } \\
\hline $\begin{array}{l}\text { 1. Proyección } \\
\text { de imágenes } \\
\text { y diálogo en } \\
\text { torno a ellas } \\
\text { (AC) }\end{array}$ & 30 minutos & $\begin{array}{l}\text { El objetivo de esta actividad } \\
\text { es que el alumnado se } \\
\text { vaya familiarizando con la } \\
\text { utilización de las metáforas } \\
\text { como mecanismo de } \\
\text { construcción de la identidad } \\
\text { nacional en el ensayo que } \\
\text { tienen que analizar y valorar. } \\
\text { En este caso, partiremos } \\
\text { de lo conocido, de lo más } \\
\text { fácilmente identificable: } \\
\text { metáforas visuales. }\end{array}$ & $\begin{array}{c}\text { Diapositivas. } \\
\text { Plataforma de } \\
\text { Enseñanza Virtual }\end{array}$ \\
\hline $\begin{array}{l}\text { 2. Lectura y } \\
\text { comentario } \\
\text { de fragmentos } \\
\text { (AC) }\end{array}$ & 30 minutos & $\begin{array}{l}\text { El objetivo de esta actividad } \\
\text { es que el alumnado se } \\
\text { vaya familiarizando con la } \\
\text { utilización de metáforas como } \\
\text { mecanismo de construcción } \\
\text { de la identidad nacional } \\
\text { dentro del ensayo que tienen } \\
\text { que analizar y valorar. Para } \\
\text { ello, utilizaremos algunos } \\
\text { fragmentos seleccionados } \\
\text { del cuadernillo de textos } \\
\text { que tienen disponible en la } \\
\text { plataforma de Enseñanza } \\
\text { Virtual. }\end{array}$ & $\begin{array}{l}\text { Diapositivas, } \\
\text { cuadernillo } \\
\text { “Textos” (cuya } \\
\text { lectura previa } \\
\text { les habremos } \\
\text { recomendado } \\
\text { en sesiones } \\
\text { anteriores). } \\
\text { Plataforma de } \\
\text { Enseñanza Virtual }\end{array}$ \\
\hline
\end{tabular}

Ciclos de Mejora en el Aula (2020). Experiencias de Innovación Docente de la US Esta obra se distribuye con la licencia Creative Commons 


\begin{tabular}{|c|c|c|c|}
\hline 3. Sintesis (C) & 10 minutos & $\begin{array}{c}\text { A partir de los comentarios } \\
\text { y aportaciones de los } \\
\text { estudiantes, la profesora } \\
\text { propondrá una síntesis de } \\
\text { las principales ideas tratadas } \\
\text { durante la sesión }\end{array}$ & $\begin{array}{c}\text { Plataforma de } \\
\text { Enseñanza Virtual }\end{array}$ \\
\hline $\begin{array}{l}\text { 4. ¿Qué tienes } \\
\text { que hacer para } \\
\text { mañana? }\end{array}$ & 10 minutos & $\begin{array}{c}\text { Recordatorio de las } \\
\text { actividades que el alumno } \\
\text { tiene que hacer para al día } \\
\text { siguiente y de las vías de } \\
\text { comunicación. Resolución de } \\
\text { dudas }\end{array}$ & $\begin{array}{c}\text { Diapositivas. } \\
\text { Plataforma de } \\
\text { Enseñanza Virtual }\end{array}$ \\
\hline \multicolumn{4}{|c|}{ CUARTA SESIÓN } \\
\hline $\begin{array}{c}\text { Trabajo } \\
\text { autónomo del } \\
\text { alumnado (AC) }\end{array}$ & 80 minutos & $\begin{array}{c}\text { A través de los grupos o "Islas" } \\
\text { habilitados en la plataforma, } \\
\text { los estudiantes trabajarán en } \\
\text { la realización del proyecto o } \\
\text { "Actividad final" en grupos } \\
\text { de cinco personas, contando } \\
\text { siempre con la orientación } \\
\text { o acompañamiento de la } \\
\text { profesora }\end{array}$ & $\begin{array}{c}\text { Plataforma de } \\
\text { Enseñanza Virtual }\end{array}$ \\
\hline \multicolumn{4}{|c|}{ QUINTA SESIÓN } \\
\hline $\begin{array}{l}\text { Trabajo } \\
\text { autónomo del } \\
\text { alumnado (AC) }\end{array}$ & 80 minutos & $\begin{array}{c}\text { A través de los grupos o "Islas" } \\
\text { habilitados en la plataforma, } \\
\text { los estudiantes trabajarán en } \\
\text { la realización del proyecto o } \\
\text { "Actividad final" en grupos } \\
\text { de cinco personas, contando } \\
\text { siempre con la orientación } \\
\text { o acompañamiento de la } \\
\text { profesora. }\end{array}$ & $\begin{array}{c}\text { Plataforma de } \\
\text { Enseñanza Virtual }\end{array}$ \\
\hline \multicolumn{4}{|c|}{ SEXTA SESIÓN } \\
\hline $\begin{array}{l}\text { 1. Puesta en } \\
\text { común por } \\
\text { grupos y } \\
\text { recapitulación } \\
\text { de ideas (AC } \\
\text { +C) }\end{array}$ & 60 minutos & $\begin{array}{l}\text { Un representante de cada } \\
\text { uno de los grupos o Islas } \\
\text { comparte con el resto de la } \\
\text { clase las principales ideas } \\
\text { sobre las que su grupo } \\
\text { ha estado trabajando. La } \\
\text { profesora toma nota de esas } \\
\text { ideas y las incorpora a las } \\
\text { diapositivas de clase }\end{array}$ & $\begin{array}{c}\text { Diapositivas. } \\
\text { Plataforma de } \\
\text { Enseñanza Virtual }\end{array}$ \\
\hline
\end{tabular}

Ciclos de Mejora en el Aula (2020). Experiencias de Innovación Docente de la US Esta obra se distribuye con la licencia Creative Commons 


\begin{tabular}{|c|c|c|c|}
\hline Síntesis (C) & 10 minutos & $\begin{array}{c}\text { A través de una serie de textos } \\
\text { e imágenes procederemos a } \\
\text { contrastar y recapitular las } \\
\text { ideas trabajadas durante las } \\
\text { sesiones anteriores }\end{array}$ & $\begin{array}{c}\text { Diapositivas. } \\
\text { Plataforma de } \\
\text { Enseñanza Virtual }\end{array}$ \\
\hline $\begin{array}{c}\text { 3. ¿Qué tienes } \\
\text { que hacer? }\end{array}$ & 10 minutos & $\begin{array}{c}\text { Recordatorio de la fecha de } \\
\text { entrega de la "Actividad final" } \\
\text { y de las vías de comunicación. } \\
\text { Se les recomienda realizar la } \\
\text { encuesta de satisfacción } \\
\text { Los estudiantes también } \\
\text { podrán plantear dudas sobre } \\
\text { el desarrollo de la "Actividad } \\
\text { final" }\end{array}$ & $\begin{array}{c}\text { Diapositivas. } \\
\text { Plataforma } \\
\text { de Enseñanza } \\
\text { Virtual. Google } \\
\text { Drive }\end{array}$ \\
\hline
\end{tabular}

\section{Cuestionario inicial-final}

Siempre partimos de la idea de "el aprendizaje es el resultado de la interacción entre los significados que están en la mente del que aprende y las informaciones que le llegan del exterior" (Alba y Porlán, 2017: 40). Por ello, en la primera sesión, tras la presentación de las actividades y herramientas que vamos a utilizar, así como del sistema de evaluación, realizamos un cuestionario para comprobar cuáles eran los conocimientos e ideas previas de los estudiantes. Este cuestionario lo realizarian nuevamente los estudiantes al terminar el CIMA.

\section{Tabla 2. Preguntas del cuestionario}

Responde con sinceridad a las siguientes preguntas:

1. ¿Crees que la identidad es algo individual o colectivo? Razona tu respuesta.

2. ¿Qué es para ti la identidad nacional?

3. ¿Qué es lo primero en lo que piensas al escuchar "Puerto Rico"? ¿Por qué?

4. Señala tres palabras o ideas que utilizarías para definir la "identidad puertorriqueña".

5. ¿Crees que Puerto Rico es un país? Razona tu respuesta

6. ¿Qué es una metáfora? ¿Para qué crees que sirven? Señala un ejemplo de metáfora o imagen.

Para garantizar que los estudiantes que estaban siguiendo

Ciclos de Mejora en el Aula (2020). Experiencias de Innovación Docente de la US Esta obra se distribuye con la licencia Creative Commons 
la sesión desde sus casas también pudieran realizar el cuestionario, utilizamos la herramienta "Encuestas" que está disponible en la plataforma de Enseñanza Virtual de la Universidad de Sevilla.

\section{Aplicación del CIMA}

\section{Diario de las sesiones}

La primera sesión se realizó todavía con un sistema híbrido en el que un tercio de la clase podía asistir de forma presencial y los dos tercios restantes seguían la clase de forma síncrona desde casa. Había 10 alumnos en el aula y 32 conectados a la plataforma de Enseñanza Virtual. El comienzo de la clase se vio afectado por problemas técnicos, lo que hizo que se produjese un cierto retraso respecto a la temporalización prevista en el diseño inicial del CIMA. Además, durante la realización del cuestionario algunos estudiantes tuvieron problemas para acceder a la encuesta, aunque afortunadamente pudimos solventarlo sobre la marcha. En cuanto al tiempo previsto para la realización del cuestionario inicial (20 minutos), la mayoría del alumnado terminó en quince minutos, por lo que podría ser conveniente reajustar el tiempo asignado a esta actividad. En general, el alumnado se mostró interesado y participativo a la hora de debatir sobre las respuestas del cuestionario y pudimos ver opiniones diversas. El clima de trabajo fue positivo a pesar de que este modelo híbrido de enseñanza se presta fundamentalmente para la continuación de modelos tradicionales de enseñanza, es decir, modelos transmisivos. Por último, para asegurarnos de que se desarrollaba el debate entre los distintos participantes tuvimos que repetir lo que decían los estudiantes que se encontraban en clase para que lo captase el micrófono.

Ciclos de Mejora en el Aula (2020). Experiencias de Innovación Docente de la US Esta obra se distribuye con la licencia Creative Commons 
La segunda sesión se vio completamente afectada por los problemas técnicos. Después de 50 minutos intentando que funcionara el ordenador de la clase, tuvimos que marcharnos sin poder dar la clase. Tras disculparnos con los alumnos a través de un correo electrónico, para tratar de solventar lo sucedido y recuperar la sesión creamos un documento con varios fragmentos de los textos que debíamos haber visto en esa sesión e incorporamos un archivo de audio explicando la nueva actividad alternativa y algunas cuestiones clave. A modo de actividad de contraste, propusimos a los estudiantes que extrajeran las ideas más importantes de los fragmentos y las pusieran en relación con los contenidos del bloque. Dieciocho estudiantes participaron activamente en el foro de debate, un número similar al que solía pedir la palabra normalmente en las sesiones.

La tercera sesión fue la última que desarrollamos a través del sistema híbrido o mixto de enseñanza. Solamente asistieron de forma presencial dos alumnos y se conectaron cincuenta y seis a la plataforma. Comenzamos proponiendo una actividad de sintesis a partir de las ideas que los propios estudiantes habían propuesto en el foro de debate. A continuación, tomaron la palabra los estudiantes, quienes fueron comentando sus ideas a partir de las imágenes y los textos propuestos. En general, podemos decir que se estableció un clima de trabajo positivo y que la participación fue más numerosa, fundamentalmente a través del uso del chat.

La cuarta sesión se desarrolló de manera 100\% virtual. Después de plantear una serie de cuestiones generales para toda la clase, cada uno de los grupos o Islas pasó a trabajar de forma autónoma en la sesión de Collaborate de los grupos que habíamos creado en la plataforma. La profesora fue uniéndose a cada una de las sesiones para ver cómo iba avanzando cada grupo en la elección del 
tema y/o en la elaboración del trabajo. En general, los estudiantes se muestran mucho más participativos en este tipo de sesiones en grupos reducidos: conectan los micros, plantean dudas, se expresan abiertamente y dialogan. Sin embargo, nos enfrentamos frecuentemente a la dificultad de que los estudiantes no están acostumbrados a tener tanta libertad a la hora de elegir un tema, lo que hizo que muchos grupos se atascaran en este primer paso a pesar de que les habíamos sugerido algunos temas a modo de ejemplo. Asimismo, el hecho de tener que dedicarle más atención a estos grupos que tenían más dificultades hizo que no nos diera tiempo de visitar las 13 Islas, quedándonos al final de la sesión con 5 grupos pendientes.

La quinta sesión se desarrolló también de forma 100\% virtual. Para intentar compensar el hecho de que en la sesión anterior no habíamos podido hablar con todos los grupos, dimos prioridad a esas cinco Islas que habían quedado pendientes. Una vez terminado este recorrido, pasamos a atender a los demás grupos bajo demanda, es decir, nos conectábamos a la sesión de aquellos grupos que demandaban nuestra ayuda y, además, contestábamos a las dudas generales planteadas a través del chat grupal. Sin duda, estas sesiones de trabajo autónomo acompañadas por la docente han sido la parte más positiva del ciclo de mejora y la mayoría del alumnado ha destacado en la encuesta de satisfacción que les gustó mucho esta dinámica y que les habría gustado tener más sesiones como estas. De hecho, son varios los grupos que solicitaron tutorías grupales fuera de las horas de clase para continuar trabajando a través de Collaborate.

La sexta y última sesión se desarrolló de forma 100\% virtual (sesión síncrona). Para comenzar, la profesora realizó una actividad de síntesis de los contenidos trabajados en las sesiones anteriores, lo que supone un cambio respecto a la secuenciación inicialmente prevista en el CIMA para el último día (ver Tabla 1). A continuación, un representante de cada uno de los trece grupos o Islas señaló 
las ideas que su grupo consideraba más relevantes en relación con el artículo que estaban redactando. Estas ideas se incorporaron a las diapositivas de la clase, algo que los estudiantes valoraron de forma positiva.

\section{Evaluación del aprendizaje de los estudiantes}

Para comparar los conocimientos iniciales y finales de los estudiantes hemos partido de la realización de dos cuestionarios, uno al comienzo del CIMA y otro una vez entregada la actividad (o proyecto) final. En esta publicación incluimos las escaleras de aprendizaje que hemos elaborado a partir de las respuestas ofrecidas en ambos cuestionarios, organizadas de menor (nivel 0: NS/NC) a mayor grado de complejidad, elaboración o desarrollo de la respuesta (nivel 3).

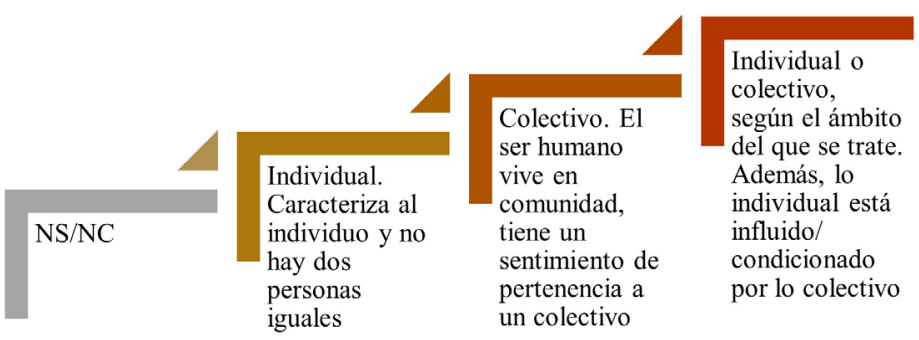

Figura 3. ¿Crees que la identidad es algo individual o colectivo? Razona tu respuesta.

En la primera pregunta del cuestionario inicial (Figura 3), una tercera parte de los estudiantes respondió que la identidad era algo individual, cinco respondieron que era algo colectivo y más de la mitad estaba ya en el escalón más alto, es decir, consideraban que era algo tanto individual como colectivo. Por tanto, la diferencia principal que encontramos al comparar las respuestas iniciales y finales a esta pregunta está en el hecho de que al terminar nuestro CIMA todos los alumnos que respondieron al cuestionario estaban en el último escalón y, además, sus 
respuestas eran más elaboradas y complejas que las del cuestionario inicial.

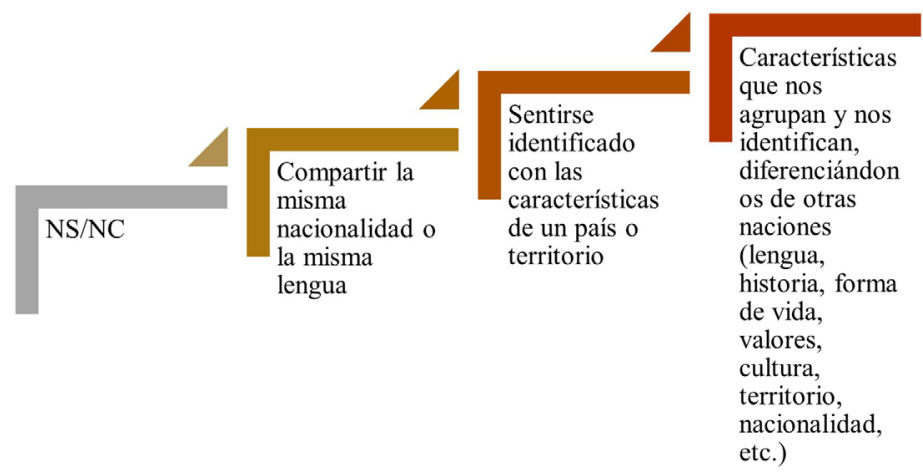

Figura 4. ¿Qué es para ti la identidad nacional?

En la segunda pregunta del cuestionario inicial, las respuestas fueron algo más variadas, aunque podemos agruparlas en los niveles recogidos en la Figura 4. La respuesta mayoritaria fue la del segundo nivel (identificación con un país o territorio), seguida del primer nivel (misma nacionalidad o lengua). Además, ocho estudiantes incluyeron las nociones de identificación y diferenciación del último nivel, bien vinculadas a cuestiones culturales, territorio o sentimiento de pertenencia. Si comparamos el cuestionario inicial y el final vemos que prácticamente la totalidad del alumnado que estaba en los niveles uno y dos han alcanzado el último nivel.

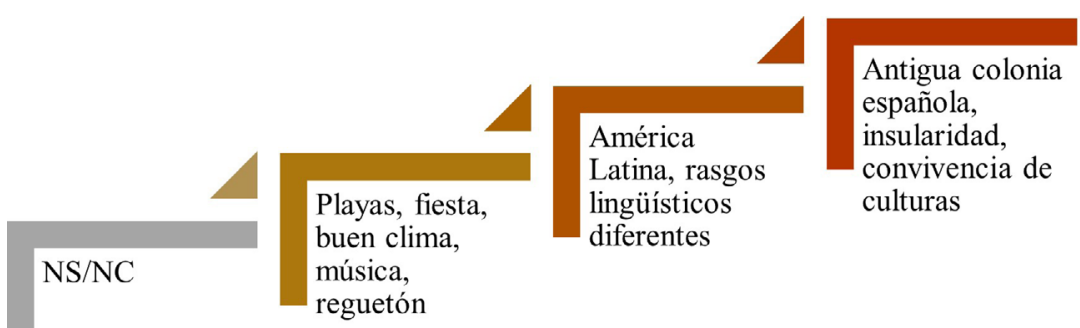

Figura 5. ¿Qué es lo primero en lo que piensas al escuchar Puerto Rico? ¿Por qué?

Ciclos de Mejora en el Aula (2020). Experiencias de Innovación Docente de la US Esta obra se distribuye con la licencia Creative Commons 
En la tercera pregunta (Figura 5) es en la que empezamos a observar un cambio más significativo en las respuestas del alumnado. En el cuestionario inicial, más de dos tercios de los estudiantes respondieron con sinceridad que lo primero en lo que pensaban al escuchar el nombre de Puerto Rico era en 'vacaciones', 'playas', 'fiesta' o 'reguetón', aunque algunos que ya había cursado la asignatura de "El Español de América" señalaron también que era un país con rasgos lingüísticos diferentes a los del español europeo. Sin embargo, en el cuestionario final las respuestas de los estudiantes son mucho más elaboradas y complejas e incorporan cuestiones que tienen que ver con la historia colonial del país, la cuestión insular o la diversidad de sus raíces culturales.

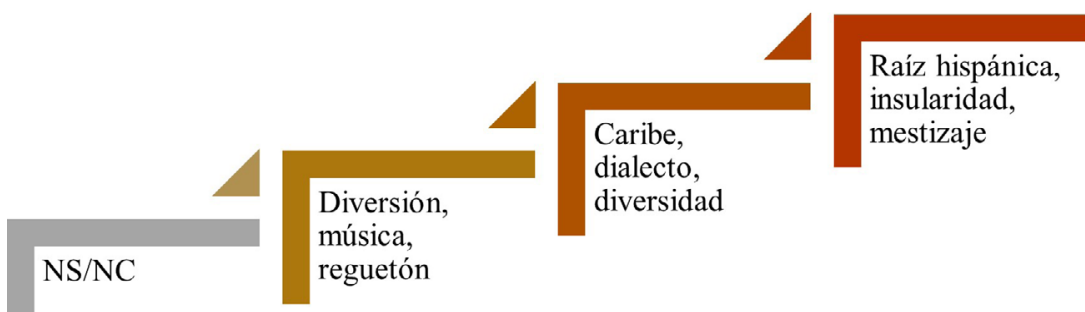

Figura 6. Señala tres palabras o ideas que utilizarías para definir la identidad puertorriqueña

La cuarta pregunta (Figura 6) está muy relacionada con la anterior. En el cuestionario inicial nos encontrábamos con un reparto prácticamente idéntico entre las respuestas NS/ NC y las que asociaban la identidad puertorriqueña con los conceptos de 'diversión', 'música' o 'reguetón' (u otros similares). Sin embargo, en el cuestionario final comprobamos que ha habido un salto cualitativo significativo puesto que, aunque las ideas previas de los estudiantes siguen estando ahí, todos han incorporado conceptos nuevos como 'insularidad', 'lucha anticolonial', 'negrismo' o 'mestizaje'.

Ciclos de Mejora en el Aula (2020). Experiencias de Innovación Docente de la US Esta obra se distribuye con la licencia Creative Commons 
$\mathrm{NS} / \mathrm{NC}$

No, pertenece a

Sí porque tiene

una cultura y

una identidad

propia

Es un Estado

Libre Asociado

a EEUU y no

tiene soberaría

nacional.

Culturalmente

tienen

características

propias y la

literatura ha

servido para

construir la

identidad

nacional

Figura 7. ¿Crees que Puerto Rico es un país? Razona tu respuesta

En el cuestionario inicial, la quinta pregunta (Figura 7) tuvo un reparto de respuestas prácticamente equitativo entre los tres primeros escalones. Encontramos respuesta del tipo "no lo sé" o "no tengo suficiente información", pero también "no, depende de Estados Unidos" o "creo que sí porque tienen una cultura diferente". Si comparamos estas respuestas con las del cuestionario final, vemos que más de dos tercios de los estudiantes establecen ya la distinción entre el hecho de que políticamente Puerto Rico sea un Estado Libre Asociado a Estados Unidos y culturalmente tenga unas características propias que lo distinguen y lo singularizan, por lo que podemos hablar también de la existencia de una literatura nacional puertorriqueña.

Ciclos de Mejora en el Aula (2020). Experiencias de Innovación Docente de la US Esta obra se distribuye con la licencia Creative Commons 
Es un recurso literario que establece una relación de semejanza entre dos cosas. Ej. Las perlas de tu boca
Se utiliza en el lenguaje cotidiano y en el literario para establecer una analogía entre un término real y otro evocado. Ej. Mi hermano es un roble
Forma parte del lenguaje cotidiano y del literario. Pueden ser también visuales. A través de una relación de semejanza entre dos elementos o realidades nos permite construir conceptos complejos como el de identidad nacional

Figura 8. ¿Qué es una metáfora? ¿Para qué crees que sirven? Señala un ejemplo de metáfora o imagen.

La sexta y última pregunta (Figura 8) era la más técnica desde el punto de vista filológico. Aunque en el cuestionario inicial todos los estudiantes respondieron incorporando una definición canónica del término y algún ejemplo clásico (como el que se menciona en el primer nivel de la escalera), al finalizar el CIMA en torno al 95\% del alumnado ha enriquecido el repertorio de ejemplos y ha incorporado a su definición otros aspectos recogido en el último nivel de la escalera de aprendizaje.

En definitiva, el análisis de las escaleras de aprendizaje que hemos presentado aquí, sumado al seguimiento continuo del alumnado que hemos realizado durante las distintas sesiones, nos permite comprobar que en general ha habido una evolución importante en el aprendizaje del grupo si comparamos sus conocimientos finales con los iniciales. A pesar de ello, tenemos que reconocer que el nivel inicial era ya bastante alto en las preguntas generales, siendo algo más bajo en aquellas cuestiones que tenían que ver con la realidad puertorriqueña, por lo que 
probablemente es en estas preguntas donde podemos observar una evolución más significativa. Si a esto añadimos también la evaluación de las actividades finales presentadas por los distintos grupos o Islas, tendremos la confirmación de que la aplicación en la docencia universitaria de estas nuevas metodologías de innovación nos permite alcanzar los objetivos propuestos.

\section{Evaluación del CIMA}

La realización del CIMA en la asignatura optativa del Curso Monográfico de Ensayo Hispanoamericano ha estado enormemente condicionada por las circunstancias excepcionales que estamos atravesando como consecuencia de la crisis sanitaria.

Como ya mencionamos en el diseño del CIMA, la Facultad de Filología había optado por un sistema híbrido o mixto de docencia. Mediante este sistema, un grupo formado por un tercio de la clase asistía de forma presencial, mientras que los dos tercios restantes seguían la sesión de forma síncrona. Además, estos grupos se iban rotando semanalmente. Sin embargo, las nuevas medidas de la Junta de Andalucía tuvieron como consecuencia que se pasase a una modalidad $100 \%$ virtual, con lo que tuvimos que reajustar un poco el diseño inicial de nuestro CIMA para adaptarnos al nuevo contexto. A esto habría que añadirle el hecho de que, mientras estábamos todavía en el sistema mixto, un día no funcionaban los medios técnicos y tuvimos que cancelar la clase, estableciendo un sistema alternativo para recuperar esa sesión mediante el uso de la plataforma de enseñanza virtual, aspectos que también hemos recogido en este trabajo en el "Diario de las sesiones".

En general, tenemos que decir que la participación de los estudiantes ha sido masiva. A las sesiones se

Ciclos de Mejora en el Aula (2020). Experiencias de Innovación Docente de la US Esta obra se distribuye con la licencia Creative Commons 
conectaban entre cuarenta y sesenta alumnos cada día y un total de 65 estudiantes se inscribieron en los distintos grupos de trabajo, denominados Islas. Cada uno de esos grupos eligió un tema y trabajó de forma autónoma sobre él, contando siempre con el apoyo de la docente, quien se iba pasando por las distintas sesiones de las Islas para compartir ideas e inquietudes. Además, en cada sesión propusimos actividades de síntesis. La mayoría de estos ejercicios de síntesis los realizaban los propios estudiantes, aunque algunas veces también las realizaba la docente para incorporar o resaltar cuestiones teóricas o procedimentales, poniendo especial énfasis en los problemas detectados en cada uno de los grupos.

Por otro lado, consideramos que el hecho de que sean estudiantes de tercer y cuarto curso con bastantes conocimientos previos ha sido un aspecto que ha permitido que la aplicación del modelo metodológico propuesto haya resultado positiva. Frecuentemente, sus intervenciones en los debates de clase reflejan que tienen un buen manejo de conceptos, terminología crítica y cuestiones filológicas complejas. Además, ha sido muy útil la realización del cuestionario inicial para conocer las ideas previas del alumnado, lo que nos permitió adaptarnos mejor al nivel de la clase y no dedicar tiempo a explicar cuestiones que los estudiantes ya conocían.

Después de la aplicación de nuestro CIMA, consideramos que el planteamiento inicial de un problema o proyecto al que los estudiantes tienen que dar respuesta ha sido un buen método de trabajo. A través de este modelo no solo hemos tenido en cuenta los conocimientos previos que los estudiantes tenían sobre la materia, sino que también nos ha permitido fomentar el trabajo autónomo del alumnado y el trabajo en equipo. Por tanto, consideramos imprescindible que los estudiantes desempeñen un papel activo en el proceso de enseñanza-aprendizaje. Sin 
embargo, somos conscientes de las dificultades que existen a veces para lograr que el alumnado entienda la importancia del proyecto planteado, por lo que en el futuro trataremos de exponer de forma más clara la propuesta y de proporcionar un mayor número de recursos bibliográficos en línea que permitan el trabajo autónomo, algo que nos han pedido los propios estudiantes, pues la mayor parte de las fuentes bibliográficas propuestas eran libros que estaban en la Biblioteca de la Universidad de Sevilla y para la mayoría de los estudiantes era imposible acceder a ellos dado que se encontraban fuera de Sevilla capital y la movilidad estaba limitada.

Por último, es importante señalar que la encuesta de satisfacción que llevamos a cabo después de la aplicación del CIMA reflejó que el alumnado estaba contento con la nueva dinámica y creía que las distintas actividades de contraste propuestas les habían ayudado a mejorar su conocimiento sobre la materia. Sin embargo, algunos consideraron que había faltado dar más contenido o que esta propuesta conllevaba un trabajo mayor que otras metodologías tradicionales como la realización de un examen final, ideas que suelen aparecer cuando tratamos de aplicar metodologías innovadoras que sacan a los estudiantes de su zona de confort. En cualquier caso, la respuesta mayoritaria ha sido positiva y casi la totalidad del grupo considera que debería haber seguido aplicándose este nuevo modelo didáctico u otro similar durante todo el cuatrimestre.

\section{Una reflexión final sobre los principios didácticos}

A modo de sintesis, conviene destacar algunos principios didácticos en los que nos hemos basado para llevar a cabo este CIMA. En primer lugar, como ya hemos señalado, consideramos que el conocimiento no es algo acabado que el estudiante recibe del exterior y debe memorizar, 
sino que se construye a través de la interacción entre las ideas previas de los estudiantes y las informaciones externas para lograr así un aprendizaje significativo. Asimismo, no podemos perder de vista que estas informaciones deben integrar contenidos conceptuales, procedimentales y actitudinales. Por otro lado, es importante que los contenidos conecten con problemas relevantes a través del planteamiento de cuestiones socialmente controvertidas, lo que también fomenta el pensamiento crítico. Además, no debemos perder de vista que el estudiante es el centro del proceso de enseñanza-aprendizaje. Por ello, mi rol durante la puesta en práctica de este CIMA ha sido el de guía y orientadora, mientras que los auténticos protagonistas de las actividades de contraste han sido los miembros de las distintas Islas.

En definitiva, tras esta positiva experiencia de innovación docente en el aula, todos estos principios didácticos personales han pasado a convertirse en ejes vertebradores de mi práctica docente habitual y, por tanto, forman ya parte de mi modelo didáctico personal.

Ciclos de Mejora en el Aula (2020). Experiencias de Innovación Docente de la US Esta obra se distribuye con la licencia Creative Commons 
Palabras clave: Curso Monográfico de Ensayo Hispanoamericano, Grado en Filología Hispánica, docencia universitaria, experimentación docente universitaria, aprendizaje basado en problemas y proyectos.

Keywords: Curso Monográfico de Ensayo Hispanoamericano, Grado en Filología Hispánica, University Learning, University Teaching Innovation, Problem-Based Learning (PBL).

\section{Referencias bibliográficas}

Alba, N. de y R. Porlán (2017). La metodología de la enseñanza. En R. Porlán (Coord.), Enseñanza universitaria. Cómo mejorarla (pp. 37-53). Madrid: Morata.

Ortiz, T., Calderón, R. y Travieso, D. (2016). La enseñanza por proyectos y el aprendizaje basado en problemas (ABP): dos enfoques para la formación universitaria desde una perspectiva innovadora: curso 1. La Habana: Editorial Universitaria.

Ciclos de Mejora en el Aula (2020). Experiencias de Innovación Docente de la US Esta obra se distribuye con la licencia Creative Commons 